Supplement of Clim. Past, 10, 1453-1471, 2014

http://www.clim-past.net/10/1453/2014/

doi:10.5194/cp-10-1453-2014-supplement

(C) Author(s) 2014. CC Attribution 3.0 License.

(c) (i)

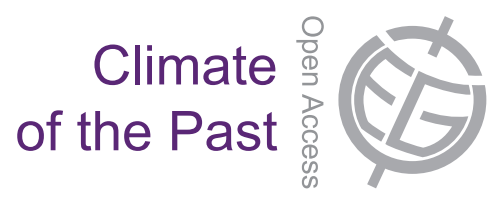

Supplement of

\title{
Evolution of the large-scale atmospheric circulation in response to chang- ing ice sheets over the last glacial cycle
}

M. Löfverström et al.

Correspondence to: M. Löfverström (marcus@misu.su.se) 
Löfverström et al., 2014, Climate of the Past, Supplementary Information

\section{S1 Eddy geopotential field}

Figures S1-S4 show the evolution of the northern hemisphere upper tropospheric (300 hPa) eddy geopotential in boreal winter and summer (DJF and JJA) in the different simulations. Results from the winter season are shown in Fig. S1 and S2 and the corresponding fields for the summer season are shown in Fig. S3 and S4. Panels in the left columns display the results from the fully forced simulations and the right columns the perturbation simulations with ice sheets eliminated (indicated by asterisks) as well as the present day reanalysis for comparison. Furthermore, Fig. S1 and S3 use the implied interglacial ocean heat transport (OHT) and Fig. S2 and S4 the LGM OHT.

The results show that the OHT has an influence on the large-scale atmospheric circulation but it is not principal for the fundamental outline and evolution of the eddy geopotential field.

Figures S1 and S2 show that the MIS 5b and MIS 4 ice sheets have a small influence on the structure of the winter eddy geopotential field regardless of the OHT. The LGM simulations, on the other hand, show a much larger impact of the ice sheets and the geopotential height gradient is zonalised over the eastern Atlantic ocean basin. The zonalisation is somewhat more prominent when using the LGM OHT (Fig. S2) and extends further east.

Figures S3 and S4 show that the choice of OHT prescription has a small influence on the glacial evolution of the upper tropospheric eddy geopotential field in the 
summer season as well. The largest changes in the eddy field are due to the evolving ice sheets and only smaller differences emerge as a result of the changes in GHG concentrations, insolation and OHT.

\section{S2 Sea-ice and jetstream in winter}

Figure S5 shows the evolution of the winter (DJF) sea-ice and $300 \mathrm{hPa}$ zonal wind in the full simulations with the two OHT prescriptions. The OHT is clearly important for the sea-ice extension in the eastern Atlantic where the interglacial ocean (left column) supports open water over the entire glacial cycle as a result of the implied heat transport in the North Atlantic Current. This warm current is much weaker in the LGM ocean (right column) due to the reduced AMOC, thus allowing the sea-ice to expand over a considerably larger area. Note that the tilt of the Atlantic jet is not principally determined by the sea-ice line although it may help to zonalise a larger section of the Atlantic jet at the LGM.

\section{S3 Summer surface temperature anomalies}

Figure S6 shows the difference in summer (JJA) surface temperature between the full and no-ice sheet simulations over the glacial cycle. The temperature response to the presence of the ice sheets develop in a similar fashion regardless of the OHT. There is a widespread warm anomaly in north-central Asia and slightly cooler temperatures over Europe and the northern Atlantic in MIS 5b. This signal is strengthened in MIS 4 and the Asian warm anomaly is shifted westwards. Northwestern North America also exhibits warmer temperatures in this case when the 
ice sheets are present.

The LGM simulations show a somewhat different picture with a general cooling of the mid- and high-latitudes with the exception of Alaska and the region east of the Eurasian ice sheet where the temperatures are slightly warmer. The cooling of the eastern Atlantic and Europe is comparable in magnitude with both OHT parameterisations despite the lack of sea-ice in the eastern Atlantic when using the interglacial OHT. 

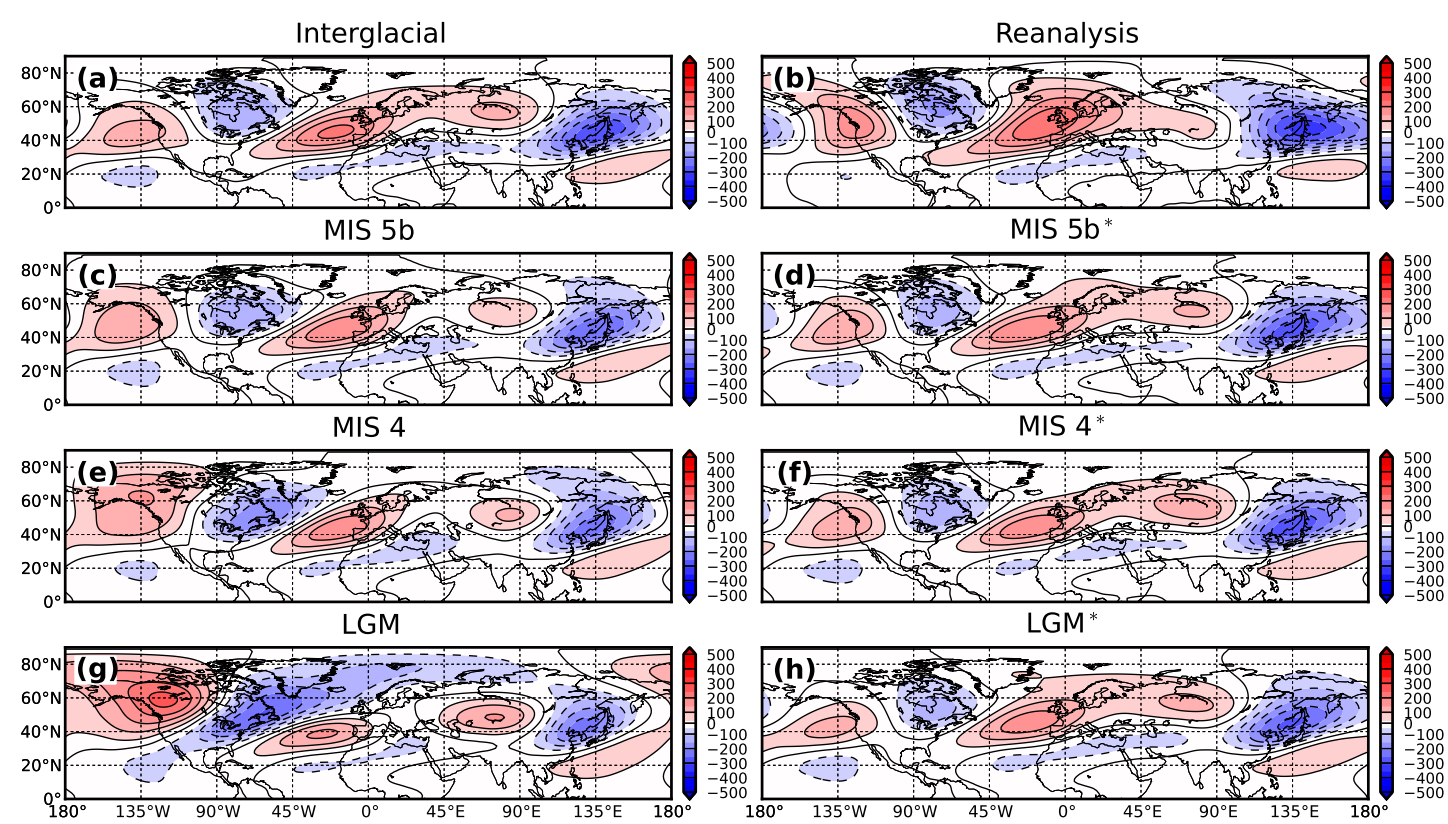

Figure S1: The $300 \mathrm{hPa}$ eddy geopotential field averaged over the winter months (DJF) in the set of simulations using the interglacial OHT. The left column shows the results from the fully forced simulations and the panels in the right column show the present day reanalysis and the results from the perturbation simulations with eliminated ice sheets (indicated by asterisks). The contour interval is $50 \mathrm{~m}$. 

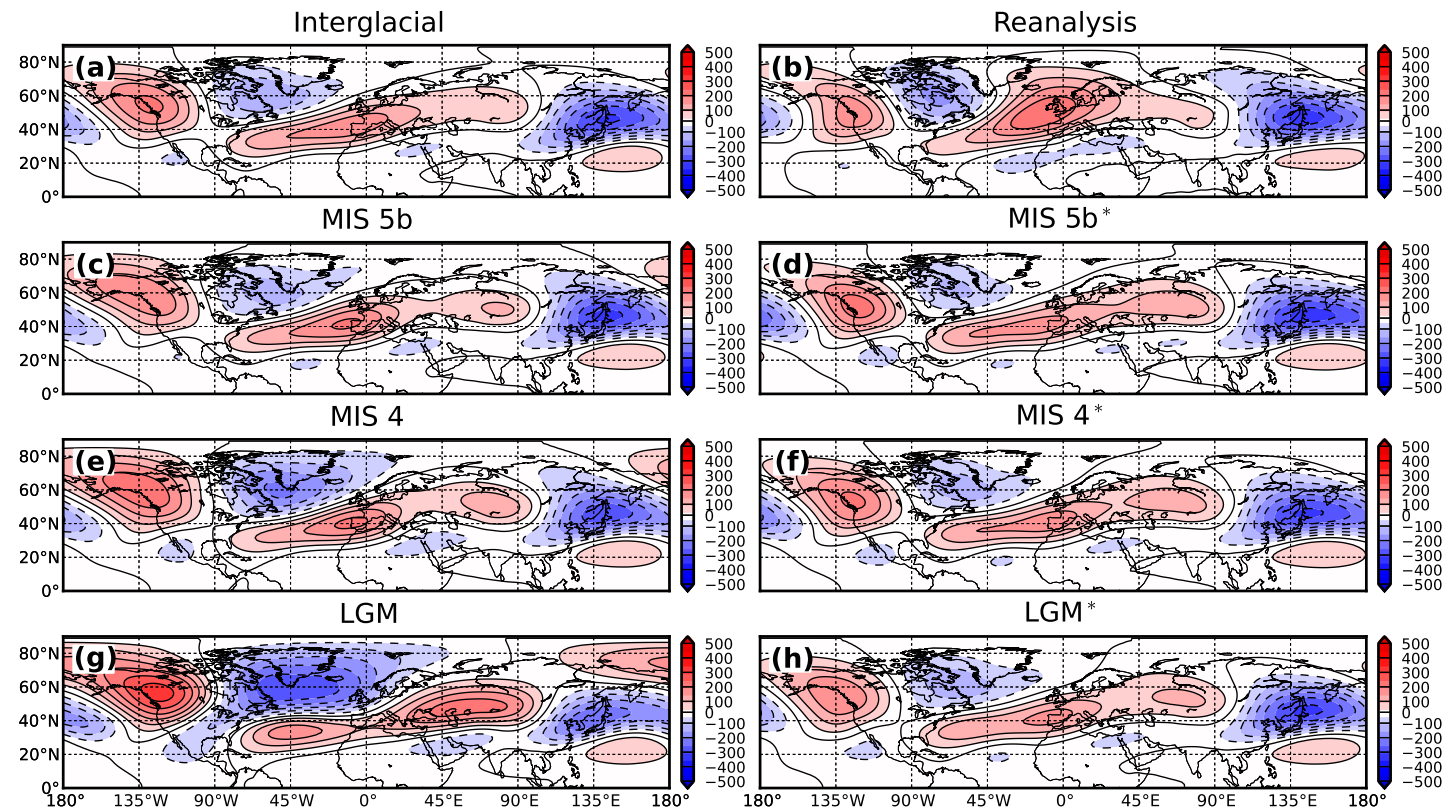

Figure S2: The $300 \mathrm{hPa}$ eddy geopotential field averaged over the winter months (DJF) in the simulations using the LGM OHT. The left column shows the fully forced simulations and the panels in the right column show the present day reanalysis and the perturbation simulations with eliminated ice sheets (indicated by asterisks). The contour interval is $50 \mathrm{~m}$. 
Interglacial
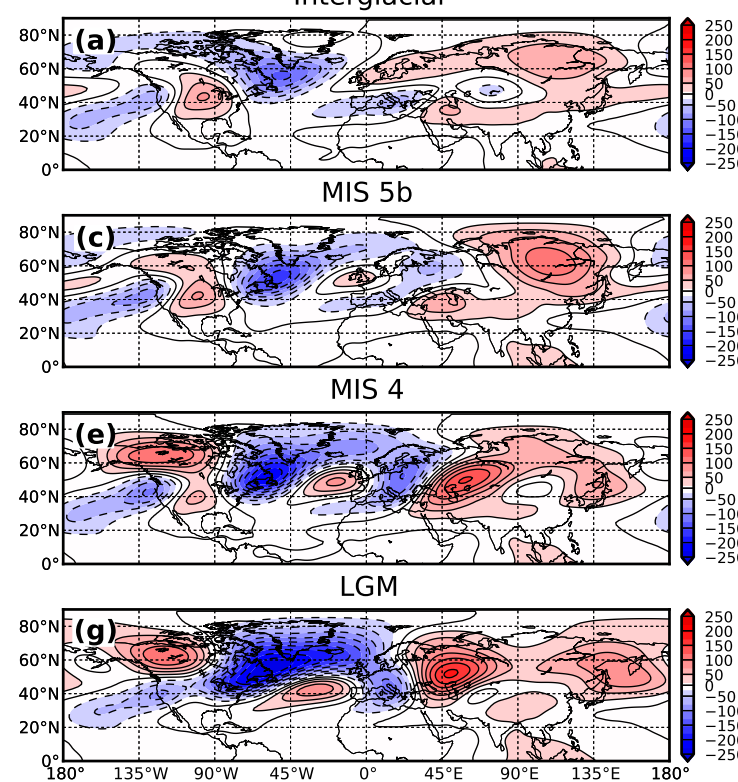

Reanalysis
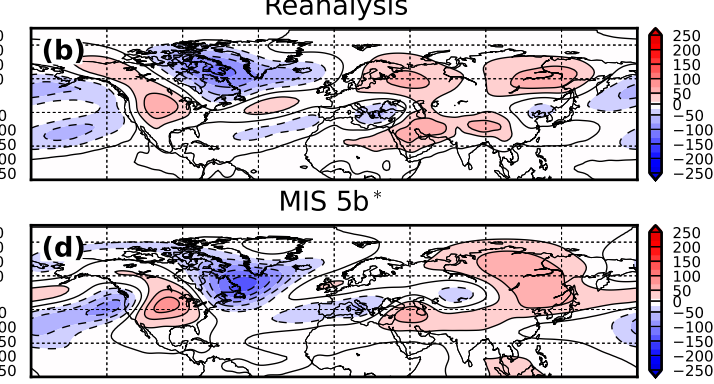

MIS $4^{*}$

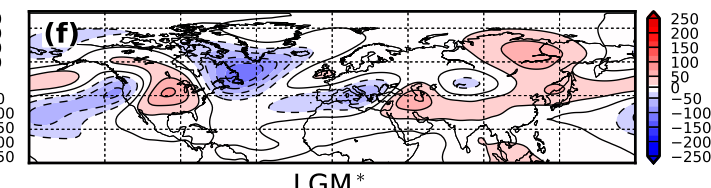

LGM*

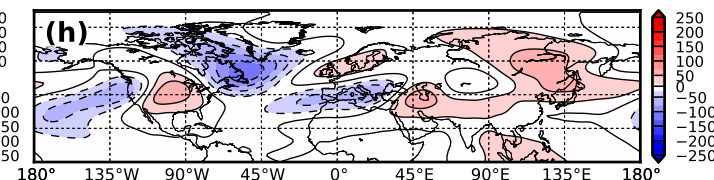

Figure S3: The $300 \mathrm{hPa}$ eddy geopotential field averaged over the summer months (JJA) in the simulations using the interglacial OHT. The left column shows the fully forced simulations and the panels in the right column show the present day reanalysis and the perturbation simulations with eliminated ice sheets (indicated by asterisks). The contour interval is $25 \mathrm{~m}$. 

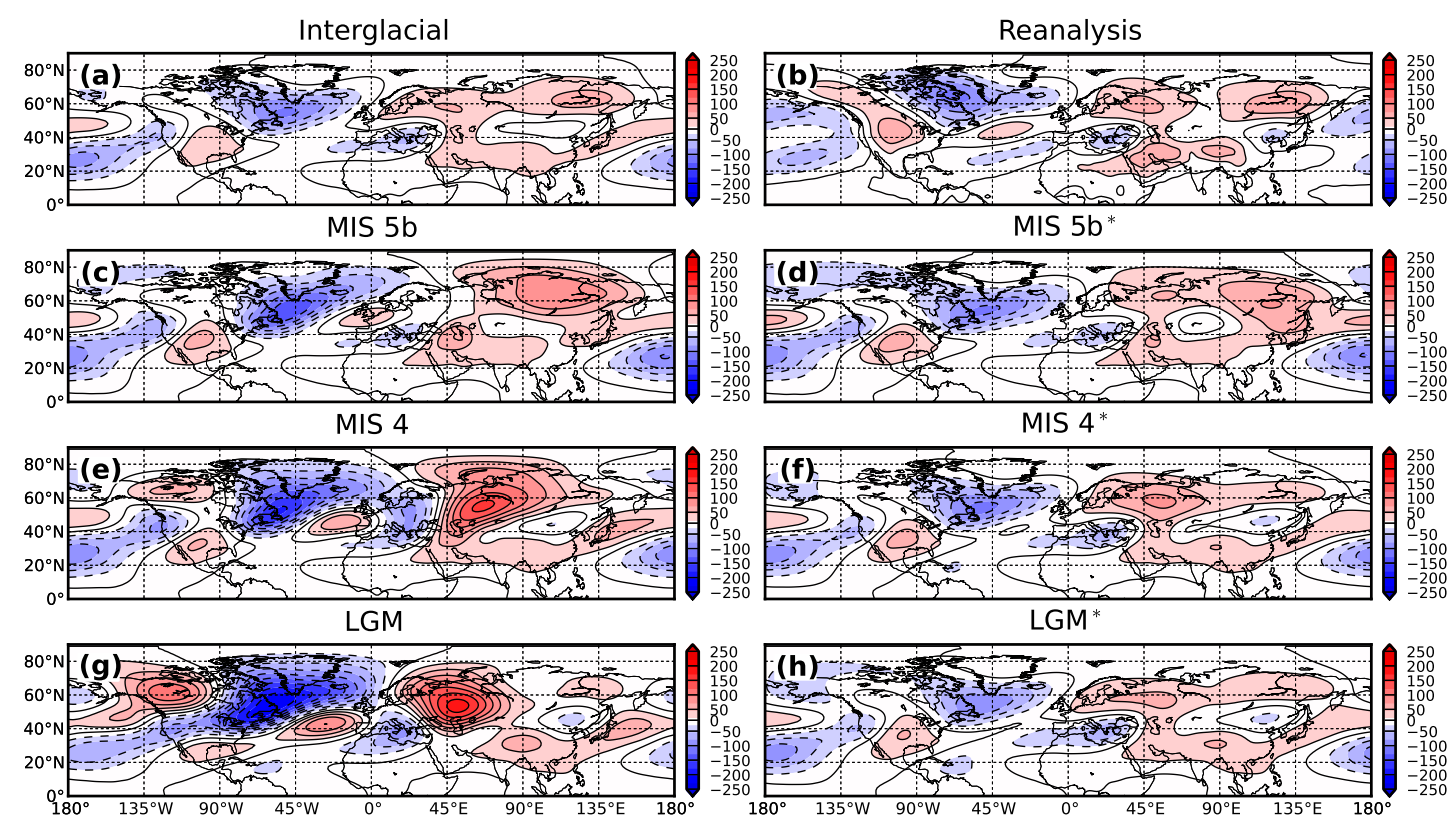

Figure S4: The $300 \mathrm{hPa}$ eddy geopotential field averaged over the summer months (JJA) in the simulations using the LGM OHT. The left column shows the fully forced simulations and the panels in the right column show the present day reanalysis and the perturbation simulations with eliminated ice sheets (indicated by asterisks). The contour interval is $25 \mathrm{~m}$. 

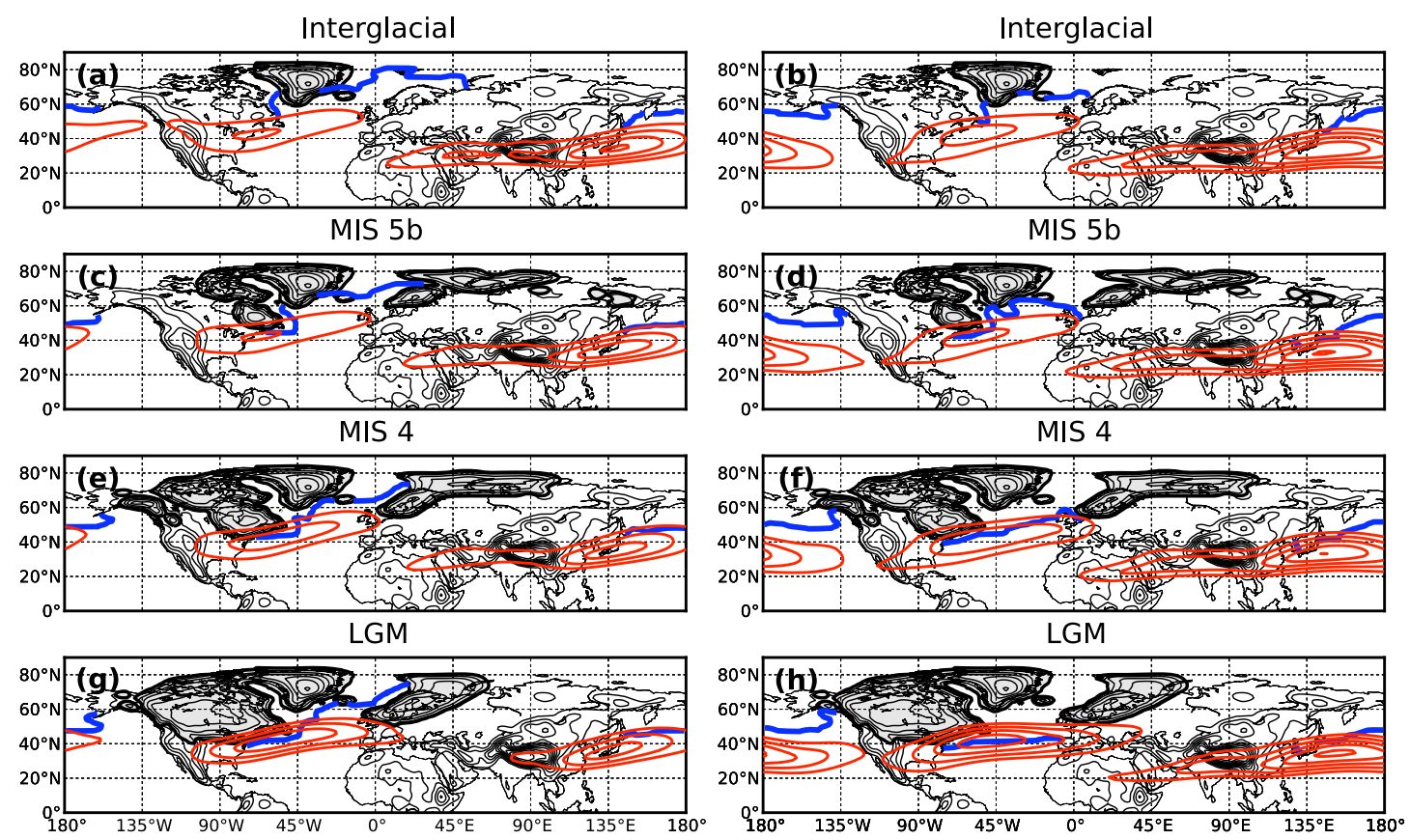

Figure S5: The red contours show the evolution of the $300 \mathrm{hPa}$ winter (DJF) zonal wind over the glacial cycle $\left(10 \mathrm{~m} \mathrm{~s}^{-1}\right.$ contours starting at $\left.30 \mathrm{~m} \mathrm{~s}^{-1}\right)$. The interglacial OHT is used in the left column and the LGM OHT in the right column. The blue contour shows the $50 \%$ sea-ice margin in the same season. 

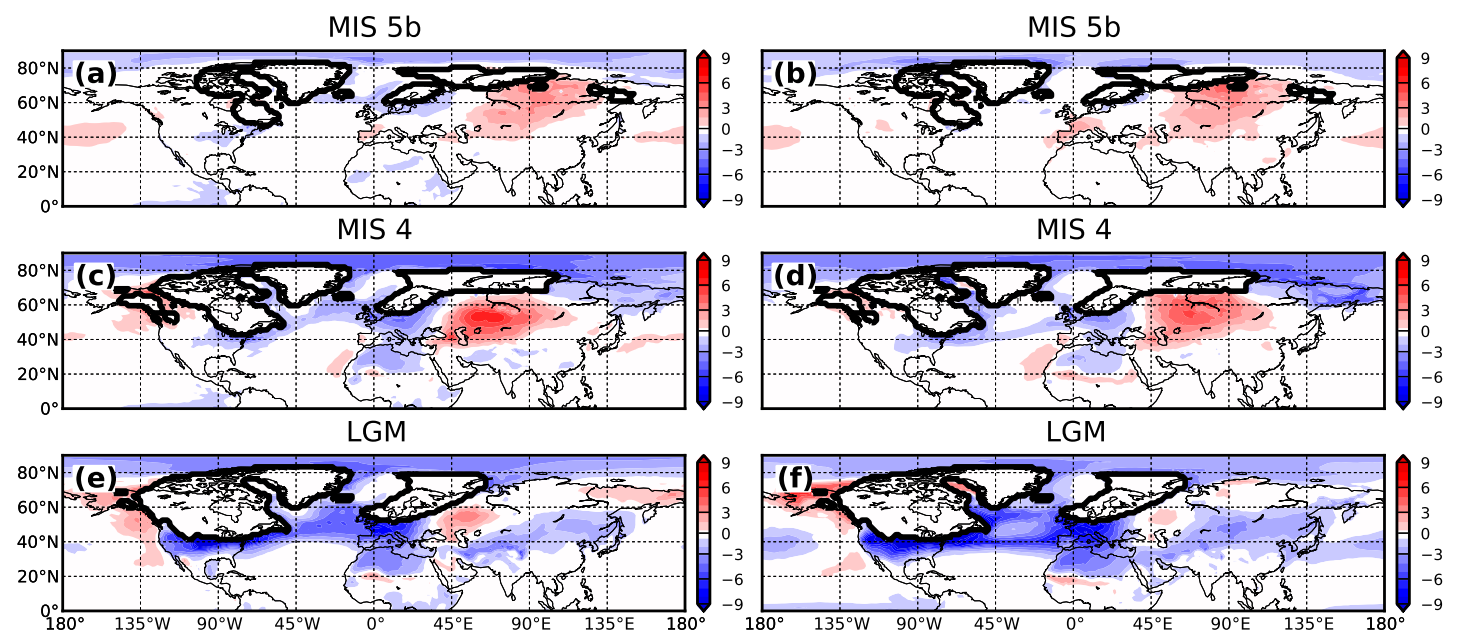

Figure S6: The difference in average summer (JJA) surface temperature (K) between the full glacial simulations and the perturbation simulations with eliminated ice sheets. The left column is based on simulations using the interglacial OHT and the right column the LGM OHT. 